\title{
Grosgrain Stockings in the Treatment of Primary Congenital Lymphedema
}

\author{
Maria de Fatima Guerreiro Godoy ${ }^{1}$ (D), Stelamarys Barufi ${ }^{2}$ (D), Paula Pereira de Godoy Capeletto ${ }^{3}$ (D), \\ Henrique Jose Pereira de Godoy ${ }^{4}(\mathbb{D})$, Jose Maria Pereira de Godoy ${ }^{5^{*}}$ (D)
}

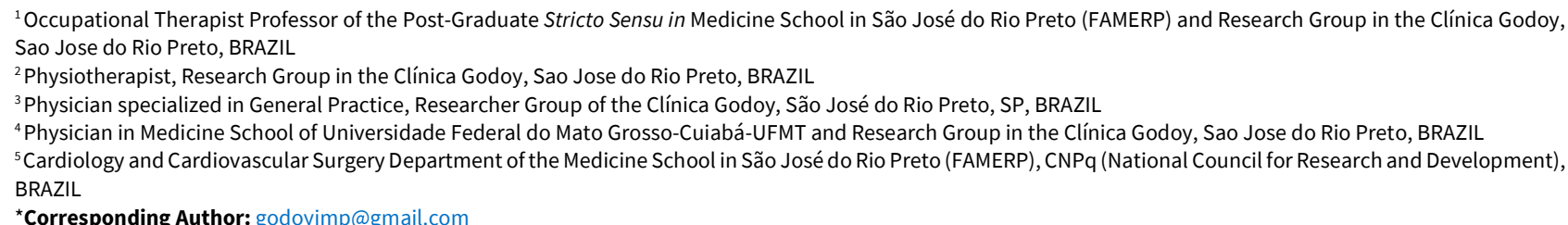

Citation: Guerreiro Godoy MdF, Barufi S, Pereira de Godoy Capeletto P, Pereira de Godoy HJ, Pereira de Godoy JM. Grosgrain Stockings in the Treatment of Primary Congenital Lymphedema. Electron J Gen Med. 2022;19(2):em354. https://doi.org/10.29333/ejgm/11565

\section{ARTICLE INFO}

Received: 1 Sep. 2020

Accepted: 26 Sep. 2021

\section{ABSTRACT}

Aim: The aim of the present study was to evaluate grosgrain c stockings in the reduction and maintenance of the results of treatment for lymphedema.

Method: A prospective clinical trial was performed with 45 patients who made use of grosgrain stockings as monotherapy for the treatment of lower limb lymphedema with the analysis of the volumetric reduction using bioimpedance at the Clinica Godoy-Brazil. These stockings are hand-crafted and adapted to each patient, with adjustments made as necessary.

Results: The mean reduction in volume was from 7.1 to $6.0 \mathrm{~L}$ (standard deviation: $1.56 \mathrm{~L}$ ). This reduction was statistically significant (p-value $<0.0001$, paired t-test). A total of $17(18.8 \%)$ of the 90 limbs did not undergo reductions, but rather had discrete numerical increases. However, these increases were not statistically significant in this group of patients ( $p$-value $=0.08$, paired $t$-test).

Conclusion: Grosgrain stockings are effective for the treatment of primary congenital lymphedema when used in accordance with the recommended instructions.

Keywords: lymphedema, treatment, grosgrain stockings, primary congenital

\section{INTRODUCTION}

Lymphedema is a clinical condition stemming from a failure of the lymphatic system in the formation or drainage of lymph. The cause can be congenital or secondary and aggravating factors can contribute to the increase in edema [1] The combination of therapies is recommended, such as compression mechanisms (stockings and bandages), manual and mechanical lymphatic drainage, exercises and activities of daily living [2].

Stocking or sleeves are fundamental to both treatment and the maintenance of the results. For such, circular elastic stockings or a flat fabric are the most indicated $[3,4]$. In recent years, Godoy \& Godoy have developed a novel concept involving hand-crafted stockings made of grosgrain fabric. These stockings develop both working and resting pressure and therefore meet the criteria for the compression mechanism [5-9].

Several studies have shown that these stockings can be used at all ages and reduce the volume of the limb, thereby treating lymphedema [10]. Proper continual adjustments are fundamental to achieving the best results. For such, the patient needs to be counseled and trained for the adequate use of these stockings. Weekly adjustments enable better results in comparison to bi-weekly and monthly adjustments.

The aim of the present study was to evaluate grosgrain c stockings in the reduction and maintenance of the results of treatment for lymphedema.

\section{METHODS}

\section{Patients}

Forty-five consecutive patients who made use of grosgrain stockings for lymphedema treatment of limbs who returned for follow up in a two-week period at the Clinica Godoy-Brazil in December 2018.

\section{Design}

A prospective clinical trial was performed with 45 patients who made use of grosgrain stockings as monotherapy for the treatment of lower limb lymphedema with the analysis of the volumetric reduction using bioimpedance. 
25

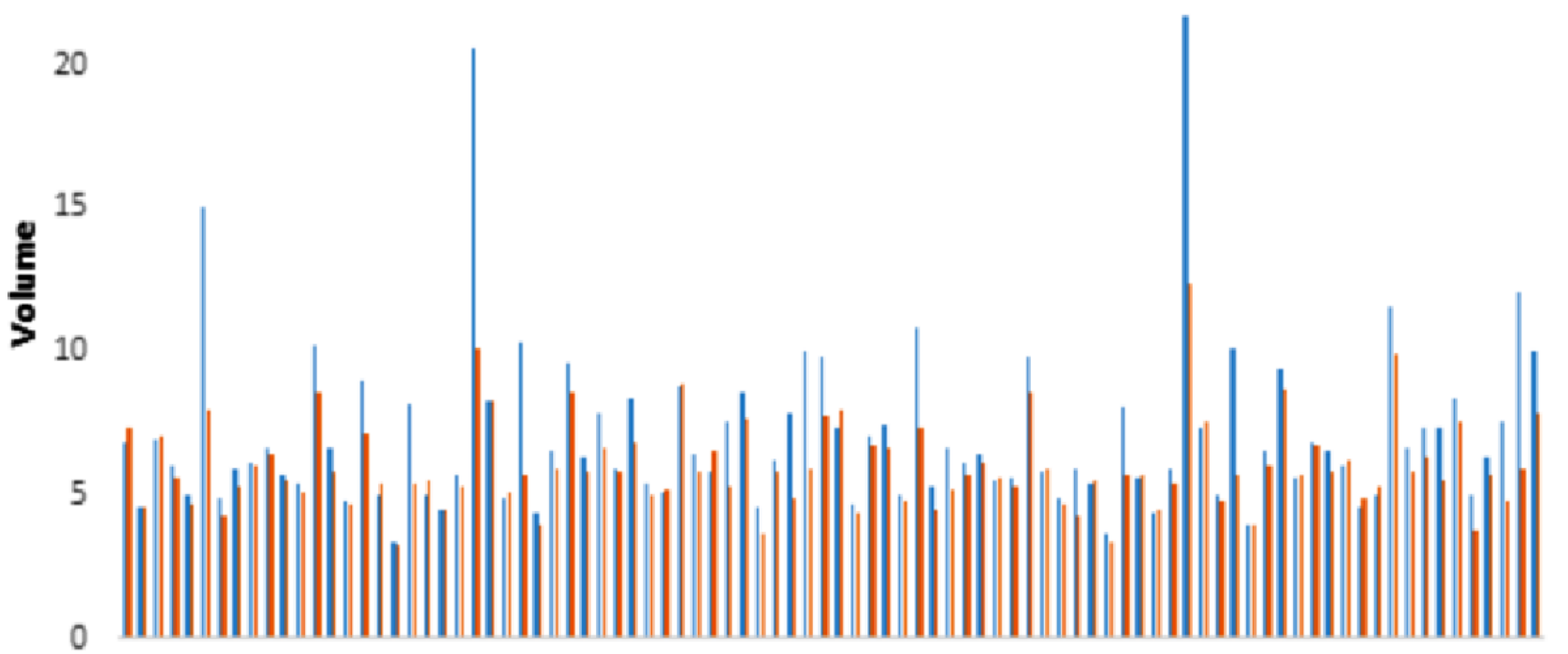

147101316192225283134374043464952555861646770737679828588

before

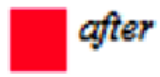

Figure 1. The variation of the volume of each limb before and after the treatment with the grosgrain stockings as monotherapy

\section{Inclusion Criteria}

Patients with primary lymphedema making use of grosgrain stockings.

\section{Exclusion Criteria}

Patients in other forms of treatment that could affect the results, such as lymphatic therapy, infection and other causes of edema diagnosed clinically.

\section{Development}

Evaluated patients with primary lymphedema of the lower limbs who made use of grosgrain stockings as monotherapy. These stockings are hand-crafted and adapted to each patient, with adjustments made as necessary. There are two types of adjustment. One is performed by the patient himself/herself, with the tightening of the stocking by adjusting the laces as needed, accompanying the reduction in edema (Figure 1). The other is made by a seamstress as the limb reduces in volume and the stocking no longer performs the function of compression. The patients were trained to place and adjust the stockings properly, returning after one week for revaluation, during which those who were not placing the stocking properly were trained further. After the learning phase, the patients were instructed to seek adjustments with a seamstress whenever necessary. The patients then returned for reevaluations when they were able, allowing for the difficulties in returning due to the distance to the clinic and other considerations. Upon each return visit, routine evaluations were performed, such as the measurement of circumferences, volumetry using the water displacement method and bioelectrical impedance analysis. For the present study, only the bioimpedance results were considered.

\section{Randomization}

Consecutive patients who returned to the clinic in the period were evaluated.

\section{Statistical Analysis}

The paired t-test was used, considering a 5\% alpha error.

\section{Ethical Considerations}

This study received approval from the Human Research Ethics Committee of São José do Rio Preto School of Medicine \# 58462.

\section{RESULTS}

The sample was composed of eight men and 37 women. Mean age was 49.9 years. The mean reduction in volume was from 7.1 to $6.0 \mathrm{~L}$ (standard deviation: $1.56 \mathrm{~L}$ ). This reduction was statistically significant ( $p$-value $<0.0001$, paired t-test). A total of $17(18.8 \%)$ of the 90 limbs did not undergo reductions, but rather had discrete numerical increases. However, these increases were not statistically significant in this group of patients ( $p$-value $=0.08$, paired t-test). Figure 1 shows the variations of the volumes of each limb before and after the treatment with the gorgurão socks as monotherapy.

\section{DISCUSSION}

The present study is part of a line of research on the use of grosgrain stockings and confirms their effectiveness in the treatment of primary lymphedema of the lower limbs. A number of previous studies evaluating different aspects of these stockings have shown that they are effective for treatment as well as maintaining the results. 
This study examined the evolution of edema in a sample of patients without rigorous control of the use of the stockings, which is closer to the real-life situation. Initial counseling and training are essential for patients to place the stockings properly and make the adjustments as needed. Reevaluations are important, as some patients follow the instructions rigorously, whereas others do not place the stocking properly. Therefore, the initial evaluations are educational, emphasizing the need to follow the proper placement and adjustment of the stockings.

Many patients are able to put the stockings on by themselves, whereas others have difficulties due to age, obesity or other factors. Such individuals require the assistance of others, who also need to receive instructions for proper placement and adjustments; otherwise, the stocking will not achieve the desired results. The reduction in volume is dynamic and the change in volume can often lead to a change in the positioning of the stocking, which can be uncomfortable and even cause injury. Therefore, counseling on these aspects is fundamental, as with any other stocking.

An increase in the volume of the limb can occur at any time due to the incorrect use of the stockings. Therefore, it is better to have as many reevaluations as possible. This study demonstrates that patients who routinely use the stockings correctly will experience a reduction in volume and the maintenance of the results with no need for constant reevaluations. However, studies have shown that weekly reevaluations lead to a greater reduction in comparison to biweekly or monthly reevaluations. Therefore, a certain degree of flexibility can be allowed in some cases, but more frequent reevaluations lead to the normalization of the limb within a shorter period of time.

Another aspect is the combination with elastic stockings after the normalization or near normalization of the edema. Elastic stockings are simpler, easier to wear and esthetically more pleasing. When alternated with grosgrain stockings, elastic stocking can maintain the results of treatment.

\section{CONCLUSION}

Grosgrain stockings are effective for the treatment of primary congenital lymphedema when used in accordance with the recommended instructions. Another aspect is the combination with elastic stockings after the normalization or near normalization of the edema.

Author contributions: Study Design: MFGG, SB, PPGC, HJPG, JMPG. Data Collection: MFGG, SB, PPGC, HJPG, JMPG. Statistical Analysis: HJPG, JMPG. Data Interpretation: HJPG, JMPG. Manuscript Preparation: MFGG, SB, PPGC, HJPG, JMPG. Literature Search: MFGG SB, PPGC, HJPG, JMPG. All authors have sufficiently contributed to the study, and agreed with the results and conclusions.

Funding: No funding source is reported for this study.

Declaration of interest: No conflict of interest is declared by authors.

\section{REFERENCES}

1. Paramanandam VS, Lee MJ, Kilbreath SL, Dylke ES. Selfreported questionnaires for lymphoedema: a systematic review of measurement properties using COSMIN framework. Acta Oncol. 2021 Jan; 21:1-13. https://doi.org/10.1080/0284186X.2020.1862422 PMid:33475033

2. Pereira de Godoy JM, Guerreiro Godoy MF, Barufi S, Pereira de Godoy HJ. Intensive Treatment of Lower-Limb Lymphedema and Variations in Volume Before and After: A Follow-Up. Cureus. 2020 Oct 1; 12(10):e10756. https://doi.org/10.7759/cureus.10756

3. Konschake W, Valesky E, Stege H, Jünger M. Evidence of compression therapy. Hautarzt. 2017 Aug;68(8):625-31. https://doi.org/10.1007/s00105-017-3999-z PMid:28577055

4. Rabe E, Partsch H, Hafner J, et al. Indications for medical compression stockings in venous and lymphatic disorders: An evidence-based consensus statement. Phlebology. 2018 Apr;33(3):163-84. https://doi.org/10.1177/0268355516689 631 PMid:28549402 PMCid:PMC5846867

5. Godoy JMP, Lopes Pinto R, Godoy LMP, Godoy MFG. Pilot Study on the Association of Different Compression Mechanisms to Maintain the Results of Lymphedema Treatment over One Year. Ann Med Health Sci Res. 2017; 7: 365-7.

6. Pereira de Godoy JM, Pereira de Godoy HJ, Lopes Pinto R, Facio FN Jr, Guerreiro Godoy MF. Maintenance of the Results of Stage II Lower Limb Lymphedema Treatment after Normalization of Leg Size. Int J Vasc Med. 2017;2017:8515767. https://doi.org/10.1155/2017/8515767 PMid:28835857 PMCid:PMC5557258

7. Lopes Pinto R, Guerreiro Godoy MF, Pereira De Godoy JM. Grosgrain and elastic stockings for the reduction of lymphedema and the maintenance of the results of treatment. Acta Phlebol 2020;21:23-5. https://doi.org/10.23736/S1593-232X.20.00463-4

8. Pereira de Godoy JM, Pereira de Godoy AC, de Fatima Guerreiro Godoy M. Synergistic effect of edema reduction by frequent adjustment of non-elastic stockings. Acta Phlebol 2017;18:97-101. https://doi.org/10.23736/S1593232X.17.00391-5

9. de Godoy JMP, de Godoy HJP, de Godoy ACP, Godoy MFG. Elephantiasis and Directed Occupational Rehabilitation. Case Rep Vasc Med. 2019 Feb 11;2019:6486158. https://doi.org/10.1155/2019/6486158 PMid:30886758 PMCid:PMC6388341

10. Pereira de Godoy HJ, Budtinger Filho R, Godoy MF, de Godoy JM. Evolution of Skin during Rehabilitation for Elephantiasis Using Intensive Treatment. Case Rep Dermatol Med. 2016;2016:4305910. https://doi.org/ 10.1155/2016/4305910 PMid:27999691 PMCid:PMC5143703 